Check for updates

Cite this: RSC Adv., 2018, 8, 16269

Received 23rd February 2018 Accepted 25th April 2018

DOI: $10.1039 / \mathrm{c} 8 \mathrm{ra01617h}$

rsc.li/rsc-advances

\section{Switch on fluorescence probe for the selective determination of lisinopril in pharmaceutical formulations: application to content uniformity testing}

\begin{abstract}
Fatma F. Mohammed, ${ }^{a}$ Khalid M. Badr El-Din ${ }^{\text {ab }}$ and Sayed M. Derayea, (D) *a
Lisinopril, an ACE inhibitor, was selectively determined in pharmaceutical products using spectrofluorimetry. The method was based on the switch on fluorescamine fluorescence as a result of its interaction with the primary amino group of the drug in the presence of aqueous borate buffer $(\mathrm{pH}$ 9.5). The fluorescence emission was measured at $475 \mathrm{~nm}$ after excitation at $390 \mathrm{~nm}$. The fluorescent product was suggested to be a diaryl pyrrolone cation which has a coplanar structure. Different experimental conditions affecting the reaction were optimized to give the maximum sensitivity. The fluorescence intensity was linear with the drug concentration in the range of $0.55-4.5 \mu \mathrm{g} \mathrm{mL}$. The method was validated according to $\mathrm{ICH}$ guidelines and the result was acceptable. The calculated limits of detection and quantitation were 0.182 and $0.55 \mu \mathrm{g} \mathrm{mL}^{-1}$, respectively. The commercially available dosage forms containing lisinopril alone or in combination with hydrochlorothiazide were effectively analyzed by the proposed method. The obtained results were in agreement with those of the reported method in respect to accuracy and precession. Moreover, the suggested method was employed to determine the content uniformity testing of the investigated dosage forms.
\end{abstract}

\section{Introduction}

Lisinopril, the third ACE inhibitor approved for use in the United States, is the lysine analogue of enalaprilat. The oral dosage of lisinopril ranges from 5 to $40 \mathrm{mg}$ daily (single or divided dosage), with 5 and $10 \mathrm{mg}$ daily being appropriate for the initiation of therapy for heart failure and hypertension, respectively. ${ }^{1}$

Different analytical methods have been developed for determination of lisinopril including; spectrophotometric $\mathrm{c}^{\mathbf{2 - 1 0}}$ spectrofluorimetric, ${ }^{\mathbf{1 0 - 1 5}} \quad$ polarographic, $^{7}$ chromatographic, ,,9,16-31 capillary electrophoretic ${ }^{32-35}$ flow injection ${ }^{36}$ and immunoassay ${ }^{37}$ methods.

The chromatographic and electrophoretic methods require expensive instruments and consume a large volume of expensive organic solvents. ${ }^{\mathbf{4}, \mathbf{1 7}-35}$ In addition, the spectrophotometric methods are less sensitive. ${ }^{2-10}$ On the other hand spectrofluorimetry is a simple and inexpensive technique although it has high sensitivity, selectivity and reliable accuracy. However, most of the reported spectrofluorimetric methods include heating, which is a time consuming step. ${ }^{10-15}$

${ }^{a}$ Analytical Chemistry Department, Faculty of Pharmacy, Minia University, Minia, Egypt.E-mail: sayed_derayea@mu.edu.eg

${ }^{b}$ Analytical Chemistry Department, Faculty of Pharmacy, Deraya University, Minia, Egypt
Fluorescamine reacts readily with primary amino groups to form highly fluorescent compounds, even though fluorescamine itself is nonfluorescent. These properties make fluorescamine ideal for detecting amino groups, especially in proteins, peptides, and amino acids.

The purpose of this study was to develop a fast, simple, sensitive, selective and applicable method for analysis of lisinopril in pure form, pharmaceutical preparations and in mixtures with hydrochlorothiazide. The existence of the primary amino group in the studied drug give it the ability to switch on the fluorescence of fluorescamine. In buffered alkaline medium $\mathrm{pH}$ 9.5, the fluorescent product have an excitation maximum at $390 \mathrm{~nm}$ and an emission maximum at $475 \mathrm{~nm}$ (Fig. 1).

\section{Experimental}

\subsection{Apparatus}

The instrument used was Perkin Elmer LS 45 Luminescence spectrometer (UK) that is connected to a PC computer loaded with the FL WINLAB ${ }^{\text {TM }}$ software and MLW Milwaukee SM 101 $\mathrm{pH}$ meter (Portugal).

\subsection{Materials and reagents}

Lisinopril was obtained as a gift from Sedico Company For Pharmaceutical Industries (Cairo, Egypt) and it was used 


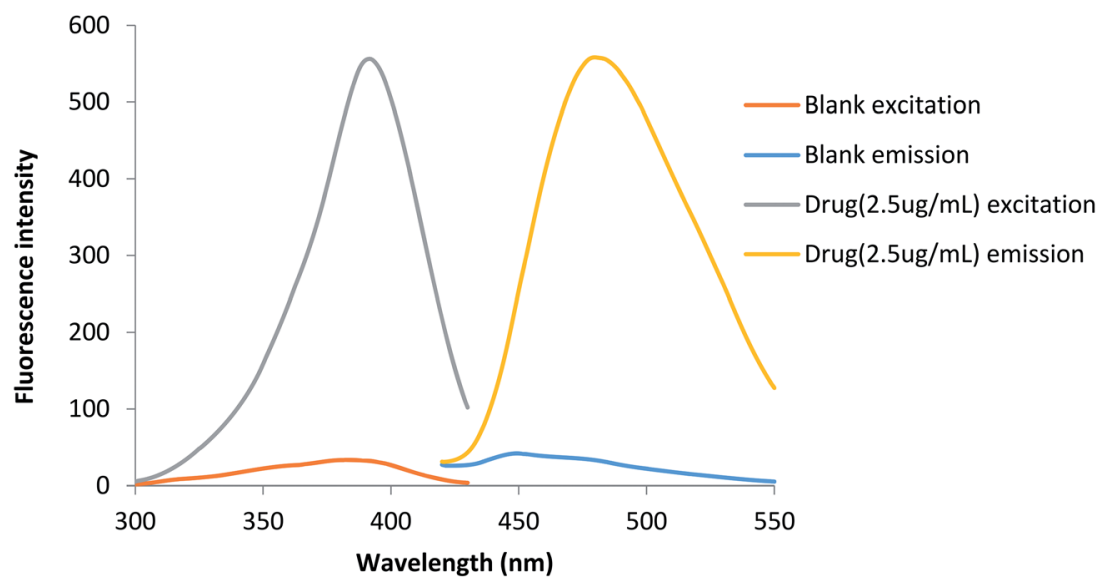

Fig. 1 The excitation and emission spectra of the blank and the reaction product between lisinopril and fluorescamine.

without further treatment. Fluorescamine (Sigma-Aldrich Chemie GmbH, Germany) and (Alfaaesar, ThermoFisher, Germany) was prepared as $0.2 \mathrm{mg} \mathrm{mL}^{-1}$ in acetone. Other chemicals such as ethanol, methanol, acetone, acetonitrile, dimethylformamide, sodium hydroxide, hydrochloric acid and boric acid were obtained from El Nasr chemical Co, Cairo, Egypt. Borate buffer was prepared by mixing $0.1 \mathrm{M}$ boric acid and $0.1 \mathrm{M}$ sodium hydroxide in amounts that are sufficient to produce $\mathrm{pH}$ 9.5. All of the materials were of analytical grade.

\subsection{Pharmaceutical formulations}

Different commercially available tablets were obtained from the local market. Maxipril ${ }^{\circledR}$ tablets (Rameda, $6^{\text {th }}$ October City, Cairo, Egypt) were labelled to contain $20 \mathrm{mg}$ of lisinopril per tablet. Sinopril Co® tablets (Global Nabi pharmaceutical Co., Egypt) were labelled to contain $20 \mathrm{mg}$ of lisinopril and $12.5 \mathrm{mg}$ of hydrochlorothiazide per tablet.

\subsection{Standard drug solutions}

A stock solution $\left(0.1 \mathrm{mg} \mathrm{mL}^{-1}\right)$ of lisinopril was prepared by dissolving $10 \mathrm{mg}$ of lisinopril in $100 \mathrm{~mL}$ volumetric flask using distilled water. Working solutions were prepared by further dilution of the stock solution with the same solvent. Different volumes of the working solution were applied in the general procedure to obtain the required final concentrations (0.5-4.5 $\left.\mu \mathrm{g} \mathrm{mL}^{-1}\right)$.

\subsection{Procedures}

2.5.1. General analytical procedure. Into a series of calibrated $10 \mathrm{~mL}$ volumetric flasks, different volumes of lisinopril solution $\left(0.05 \mathrm{mg} \mathrm{mL}^{-1}\right)$ were transferred followed by $0.5 \mathrm{~mL}$ of borate buffer $\mathrm{pH} 9.5$ and $1.0 \mathrm{~mL}$ fluorescamine solution $(0.2 \mathrm{mg}$ $\left.\mathrm{mL}^{-1}\right)$. The volume was completed to the mark with ethanol and allowed to stand for $7 \mathrm{~min}$. The fluorescence intensity of the resulting solution was measured at $475 \mathrm{~nm}$ after excitation at $390 \mathrm{~nm}$. A blank experiment was prepared simultaneously using the same procedure omitting the drug solution.
2.5.2. Preparation of sample solution. Ten tablets of the studied dosage form were weighed, finely powdered and mixed well. An amount of the finely powdered tablet equivalent to $10 \mathrm{mg}$ of lisinopril was weighed and dissolved in distilled water by sonication for $5 \mathrm{~min}$. The solution was filtered into a $100 \mathrm{~mL}$ volumetric flask and the volume was completed with distilled water to obtain a stock solution $\left(0.1 \mathrm{mg} \mathrm{mL}^{-1}\right)$. Further dilution of the stock solution was performed to prepare solution in the required range $\left(0.05 \mathrm{mg} \mathrm{mL}^{-1}\right)$. The general procedure was applied on the final solution.

2.5.3. Determination of reaction stoichiometry. Job's method of continuous variation was applied to find out the ratio between drug and the reagent. Equimolar solutions of both lisinopril and fluorescamine $\left(1.2 \times 10^{-4} \mathrm{M}\right)$ were prepared. Different solutions containing complementary volumes of the drug and the reagent solutions were prepared. The general analytical procedure was applied on each of these solutions. The fluorescence intensity was measured and Job's plot was constructed by plotting RFIs versus the corresponding mole fractions of lisinopril.

2.5.4. Procedure for content uniformity testing. The general analytical procedure was applied for the analysis of ten tablets of the studied dosage forms individually Both Sinopril ${ }^{\circledR}$ and Sinopril $\mathrm{Co}{ }^{\circledR}$ were tested for content uniformity by the proposed method. The content uniformity was performed according to the USP procedures. ${ }^{38}$ After analysing ten tablets individually the acceptance value (AV) was calculated.

\section{Results and discussion}

Fluorescamine has been widely used as a fluorigenic reagent for determination of primary and secondary amines containing drugs. It should be noted that, the reagent itself and its hydrolysis products are non-fluorescent. Upon reaction with the amino group a highly fluorescent reaction product is formed. The reaction of lisinopril through its primary aliphatic amino group turn on the fluorescence of the reagent. The reaction should be carried out in a buffered aqueous solution and the formed product has a yellow color. The fluorescence intensity of 


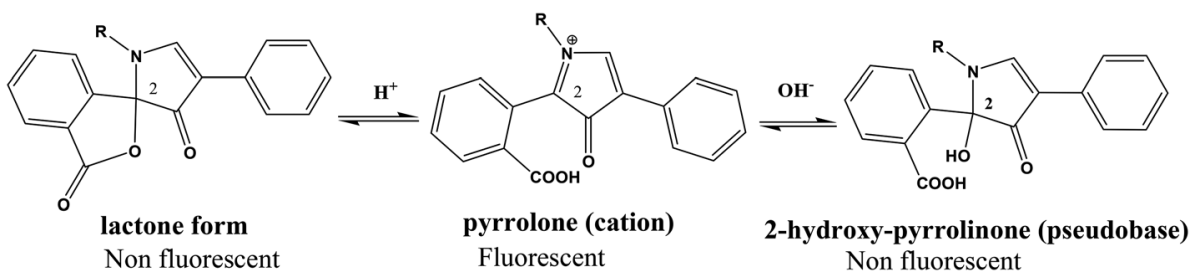

Fig. $2 \mathrm{pH}$ dependent chemical structure change of fluorescamine derivative; lactone, iminium and alkanolamine forms (R represent the lisinopril residue).

the reaction product can be measured at $475 \mathrm{~nm}$ after excitation at $390 \mathrm{~nm}$ (Fig. 1).

From the first time when fluorescamine was used as a fluorescent reagent, it has been claimed and routinely accepted that the diaryl-2-hydroxy-pyrrolinone derivative was the fluorescent product (Fig. 2).$^{39}$ However, the presence of carbon 2 of the 2hydroxy pyrrolinone molecule in the tetrahedral configuration interrupts the full conjugation of the three ring system and prevents its existence in the coplanar form (Fig. 3). As a result, the claimed reaction product which has high structural similarity to fluorescamine was expected to be deficient in any fluorescence activity. Nevertheless, it is well established that the quaternary hydroxide of $\mathrm{N}$-heterocycle could be converted into the corresponding $\mathrm{N}$-quaternary heterocyclic cation.$^{\mathbf{4 0}}$ The interconversion between the 2-hydroxy pyrrolinone and the pyrrolone cation is reversible and $\mathrm{pH}$ dependent being the
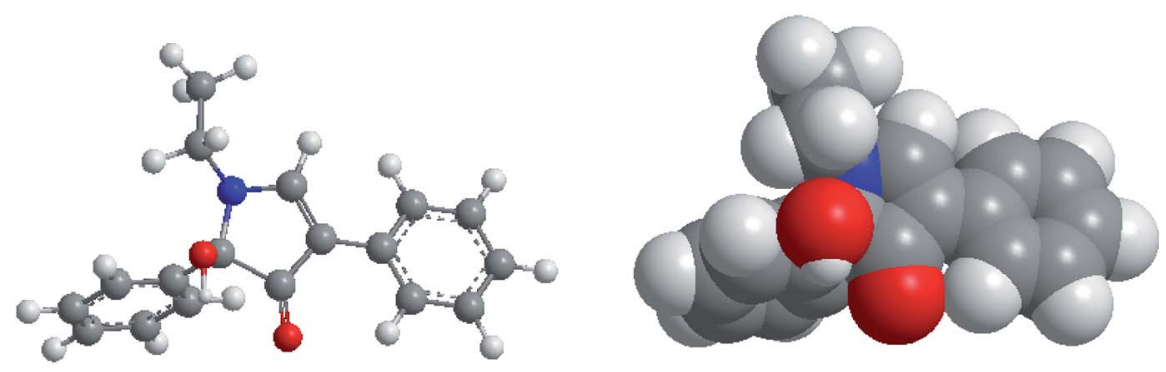

a) 2-hydroxy pyrrolinone derivative
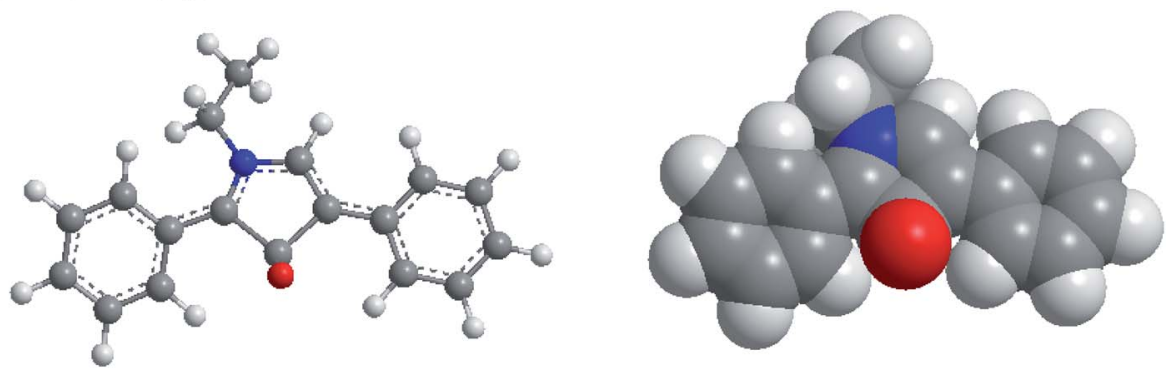

b) Pyrrolone derivative
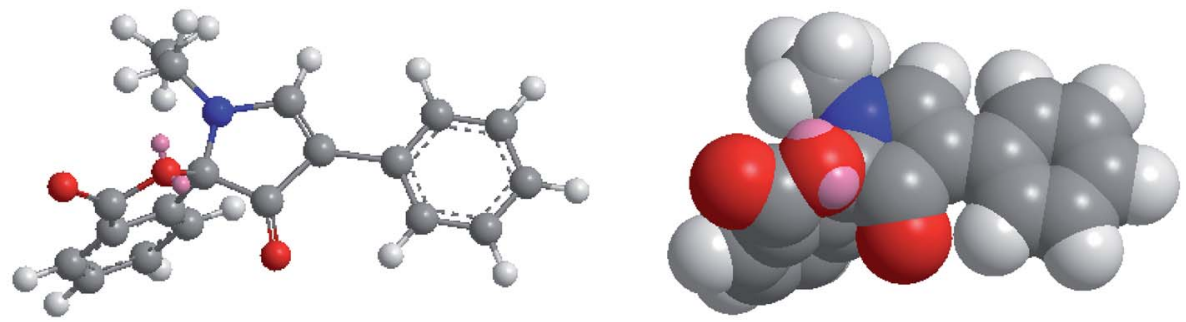

\section{c) Lactone derivative}

Fig. 3 Molecular structures (ball and sticks on the left and space filling on the right) of the possible fluorescamine derivatives showing their geometric features. Structures were create with the CS Chem3D 8 ultra software (CambridgeSoft corporation, Cambridge, MA, USA). The geometry of the structures were optimized using MM2 force field method. To simplify the structures, the nitrogen atom was linked to ethyl group instead of lisinopril residue. 
<smiles>NCCCC[C@H](N[C@@H](CCc1ccccc1)C(=O)O)C(=O)N1CCC[C@H]1C(=O)O</smiles>

Lisinopril<smiles>O=C1OC2(OC=C(c3ccccc3)C2=O)c2ccccc21</smiles>

Fluorescamine (Non fluorescent)

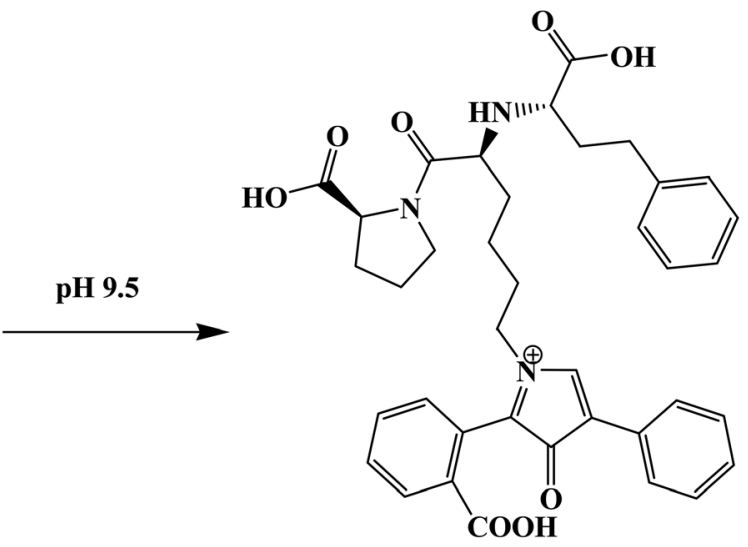

Diarylpyrrolone cation

Fluorescent product

Fig. 4 The suggested chemical reaction for the fluorescence switch of the reagent by the primary amino group of lisinopril.

hydroxylated form is predominant in the highly basic medium (Fig. 2). While the hydroxyl pyrrolinone has buckled and nonplanar structure, the pyrrolone cation is unsaturated, fully conjugated, completely planar molecule with rigid structure and hence highly fluorescent (Fig. 3). In conclusion, the planar and highly conjugated pyrrolone structure is supposed to be responsible for the fluorescence activity of the reaction product rather than the routinely reported 2-hydroxy pyrrolinone structure. A suggested reaction mechanism was presented in Fig. 4 in which the chemical derivatization proceed through the primary aromatic amino group of the drug.

\subsection{Optimization of the experimental factors}

Different experimental parameters ( $\mathrm{pH}$, fluorescamine concentration, reaction time, volume of buffer and the diluting solvent) were optimized. Each variable was changed, while keeping the other constant. In all experiments the final concentration of lisinopril was $2 \mu \mathrm{g} \mathrm{mL} \mathrm{m}^{-1}$.

3.1.1. Effect of $\mathbf{p H}$. The procedure for chemical derivatization was carried out using different types of buffers and at different $\mathrm{pH}$. It was observed that the preferred reaction medium was the faint alkaline ( $\mathrm{pH}$ 9.2-9.8). A distinct decrease in the fluorescence intensity was observed at $\mathrm{pH}$ lower or higher $\mathrm{pH}$ than this range (Fig. 5).

The loss of the emission of fluorescamine derivative in the highly acid or alkaline media could be attributed to the structural changes of that derivative (Fig. 2). At highly basic $\mathrm{pH}$, the electron-deficiency at carbon 2 of the fluorescamine product render the compound susceptible to nucleophilic substitution by the electron-rich group, hydroxide ions. Accordingly, the 2hydroxy-pyrrolinone derivative was formed. On the other hand, the loss of fluorescence at acidic $\mathrm{pH}$ may be due to the conversion of the pyrrolone derivative into the non-planar lactone. ${ }^{41}$ This lactone has a similar structure to fluorescamine itself. In addition, the carbon 2 in both the 2-hydroxypyrrolinone and lactone derivatives become tetrahedral. Consequently, the compound would be in the non-planner form with the loss of the fluorescence activity.

3.1.2. Effect of buffer type and strength. The effect of the chemical composition of the buffer was investigated using different type of buffer ( $\mathrm{pH}$ 9.5). It was found that borate buffer gave the highest reading compared with acetate, phosphate or Teorell and Stenhang buffers. Finally the influence of the buffer strength on the fluorescence intensity was studied using different volumes of borate buffer solution ( $\mathrm{pH}$ 9.5). As shown

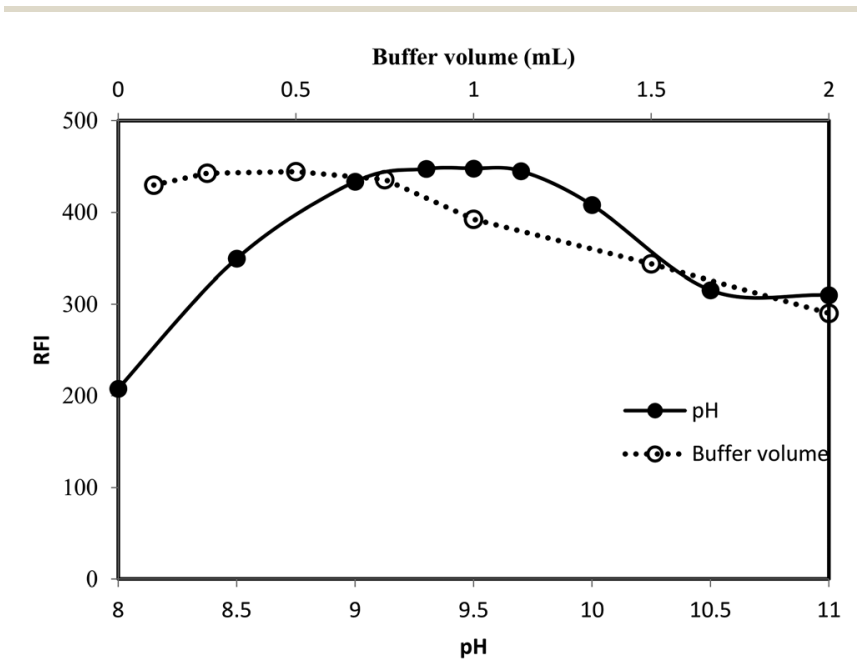

Fig. 5 Effect of $\mathrm{pH}\left(-\mathbf{-}^{-}\right)$and volume of borate buffer (- $\left.\mathrm{O}^{-}\right)$on the $\mathrm{RFI}$ of the reaction product between lisinopril $\left(2 \mu \mathrm{g} \mathrm{mL}^{-1}\right)$ and fluorescamine reagent. 
in Fig. 5, the highest reading was attained using $0.5 \pm 0.2 \mathrm{~mL}$ of the buffer. Therefore, $0.5 \mathrm{~mL}$ of borate buffer of $\mathrm{pH} 9.5$ was use throughout the work.

3.1.3. Effect of fluorescamine concentration. The effect of the reagent concentration was examined using fixed volume (1 $\mathrm{mL}$ ) of fluorescamine solutions having different concentrations (50-500 $\left.\mu \mathrm{g} \mathrm{mL}{ }^{-1}\right)$. By increasing the reagent concentration, the fluorescence intensity was gradually increased. Maximum fluorescence intensity was achieved upon using $100 \mu \mathrm{g} \mathrm{mL}^{-1}$ of fluorescamine solution. Further increase in the reagent have a negligible effect on the reading (Fig. 6). Therefore, $1 \mathrm{~mL}$ of 200 $\mu \mathrm{g} \mathrm{mL}^{-1}$ of fluorescamine solution was selected for the recommended analytical procedure.

3.1.4. Formation and stability of the reaction product. The formation of the reaction product was monitored by measuring the fluorescence intensity at interval of times. It was observed that, the reaction between the drug and the reagent was very fast and completed within very short time as the maximum fluorescence intensity was reached within $5 \mathrm{~min}$. The intensity was remained stable for at least $20 \mathrm{~min}$ at room temperature, Fig. 6. The reaction was carried out at temperature higher than room temperature $\left(25^{\circ} \mathrm{C}\right)$, but, a significant decrease in the fluorescence intensity was observed. The reduction in the intensity may be due to the high internal conversion process that occur at the elevated temperature, stimulating the non radiative deactivation of the excited singlet state. Consequently, the recommended procedure were performed at room temperature and the fluorescence intensity was measured after $7 \mathrm{~min}$.

3.1.5. Effect of diluting solvent. The formed fluorescent product was diluted with different solvent in order to select the most appropriate one. The examined solvents were water, methanol, ethanol, acetone and dimethyl formamide. Ethanol was found to be the best solvent as it gave the highest fluorescence intensity and therefore was selected for the subsequent experiments (Fig. 7).

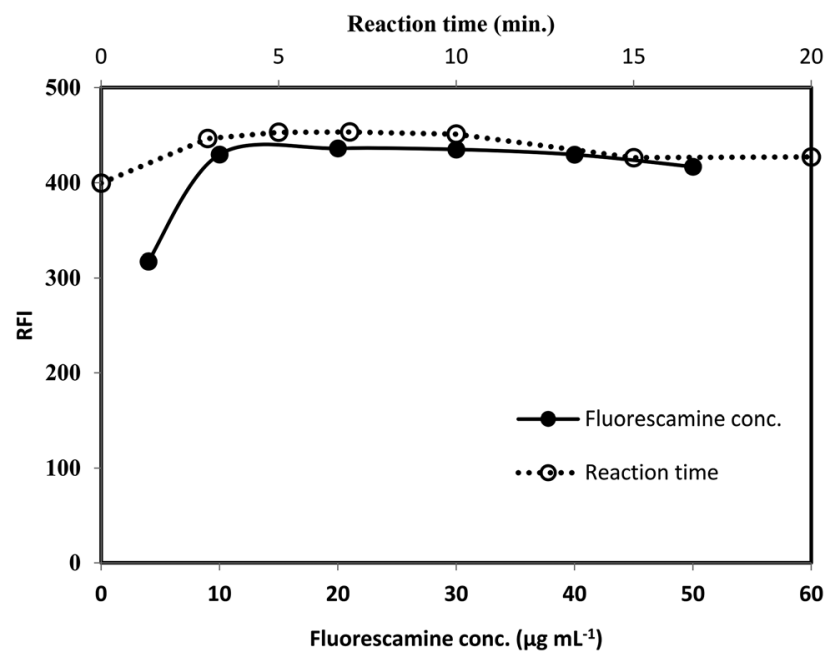

Fig. 6 Effect of fluorescamine concentration (- -) and reaction time $\left(-\mathrm{O}^{-}\right)$on the RFI of the product of reaction between lisinopril $(2 \mu \mathrm{g}$ $\mathrm{mL}^{-1}$ ) and fluorescamine reagent.

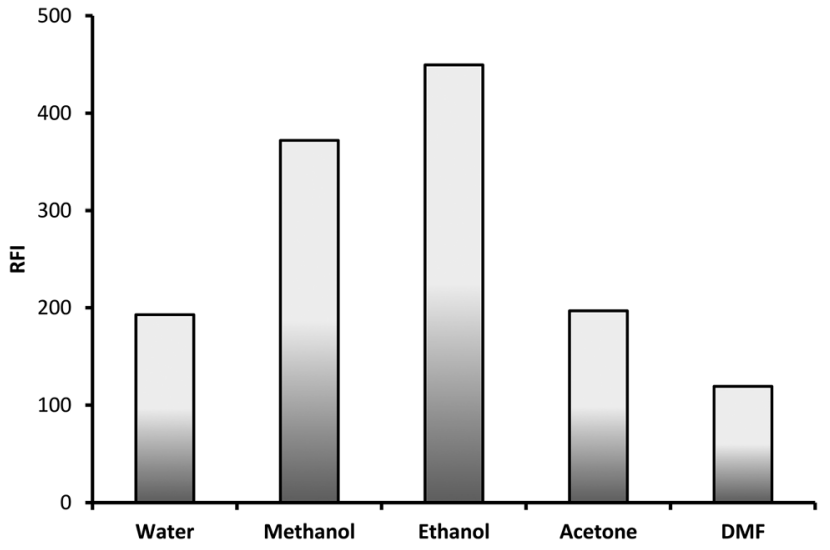

Fig. 7 Effect of diluting solvent on the RFI of the product of reaction between lisinopril $\left(2 \mu \mathrm{g} \mathrm{mL}^{-1}\right)$ and fluorescamine reagent.

\subsection{Determination of the reaction stoichiometry}

Job's method of continuous variation was applied to find out the ratio between the drug and the reagent. The reaction stoichiometry was investigated using equimolar solutions $\left(1.2 \times 10^{-4}\right.$ M) of both lisinopril and fluorescamine. The study revealed that the molar ratio between lisinopril and fluorescamine is $1: 1$ (Fig. 8). This ratio is in agreement with the suggested reaction mechanism presented in Fig. 4.

\subsection{Validation of the proposed method}

After optimization of the method parameters, the proposed method was validated by application of $\mathrm{ICH}$ guidelines ${ }^{42}$ to find out the accuracy, precision, selectivity, limit of detection and limit of quantitation.

3.3.1. Linearity and range. A series of the standard solutions containing different concentrations of lisinopril were analyzed by applying the general analytical procedure. The calibration curve was constructed by plotting the obtained RFI versus the corresponding drug concentration. Linear regression analysis was performed on the obtained data and the statistical

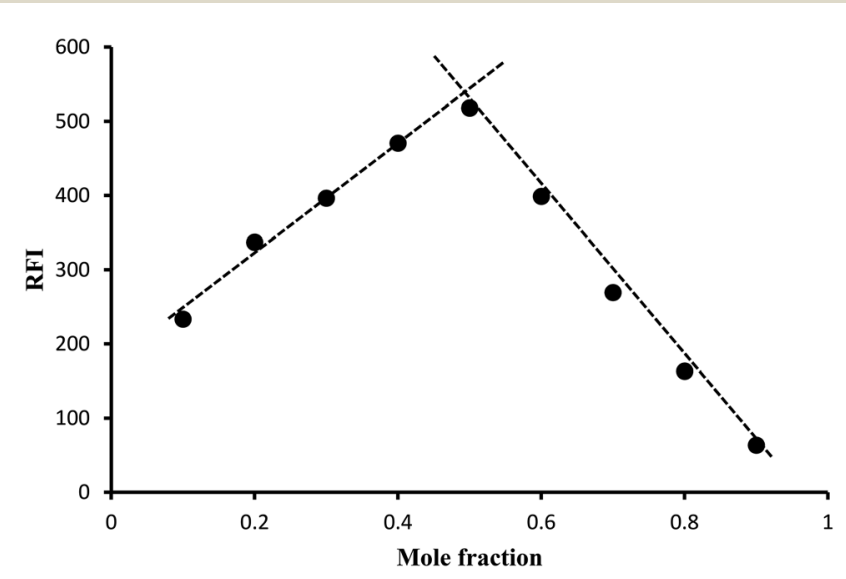

Fig. 8 Job's method for determination of the stoichiometry of the reaction by using $1.2 \times 10^{-4} \mathrm{M}$ concentration of both lisinopril and fluorescamine. 
Table 1 The statistical parameters of the proposed method for analysis of LIS

\begin{tabular}{|c|c|}
\hline Parameter & Value \\
\hline Linear range $\left(\mu \mathrm{g} \mathrm{mL}^{-1}\right)$ & $0.55-4.5$ \\
\hline Slope & 185.66 \\
\hline Standard deviation of slope $\left(S_{\mathrm{b}}\right)$ & 3.75 \\
\hline Intercept & 72.15 \\
\hline Standard deviation of the intercept $\left(S_{\mathrm{a}}\right)$ & 10.26 \\
\hline Correlation coefficient ${ }^{a}$ & 0.9986 \\
\hline Standard deviation of residuals $\left(S_{\mathrm{y}, \mathrm{x}}\right)$ & 16.56 \\
\hline Limit of detection (LOD, $\mu \mathrm{g} \mathrm{mL} \mathrm{m}^{-1}$ ) & 0.182 \\
\hline Limit of quantitation (LOQ, $\mu \mathrm{g} \mathrm{mL}^{-1}$ ) & 0.552 \\
\hline
\end{tabular}

parameters are calculated (Table 1). It was found that the drug concentration is linear with RFI in the range $0.55-4.5 \mu \mathrm{g} \mathrm{mL}^{-1}$ with high linearity $\left(r^{2}=0.9986\right)$.

3.3.2. Detection and quantitation limits. The sensitivity of the method was evaluated by calculating the limits of detection (LOD) and quantitation (LOQ). The calculation was performed according to the equations; $\mathrm{LOD}=3.3 \mathrm{\sigma} / \mathrm{S}$ and $\mathrm{LOQ}=10 \mathrm{\sigma} / \mathrm{S}$, where $S$ is the slope of the calibration curve and $\sigma$ is the standard deviation of intercept. The calculated LOD and LOQ are 0.18 and $0.55 \mu \mathrm{g} \mathrm{mL}{ }^{-1}$, respectively. These limits indicate the high sensitivity of the developed method compared with the reported spectrophotometric methods, ${ }^{2-10}$ and spectrofluorimetric method based on condensation with naphthylamine $^{\mathbf{1 3}}$ (Table 2). Although the reported spectrofluorimetric methods applying Hantzsch reaction ${ }^{\mathbf{1 0}}$ or nucleophilic substitution with NBD-Cl ${ }^{\mathbf{1 1}}$ had higher sensitivity than the proposed method, both were time consuming and tedious. In addition, all the reported spectroflourimetric methods were carried out at elevated temperatures. On the other hand, the developed procedure is fast, involves single step reaction, utilizes a single reagent and is carried out at room temperature. Despite the fact that fluorescamine is not the cheapest reagent on the shelf, the sensitivity of the method may result in a much lower price per sample. A comparison of the proposed method with the previously reported spectrophotometric and spectrofluorimetric methods is summarized in Table 2 .

3.3.3. Accuracy and precision. Standard addition method was applied to evaluate the accuracy of the method. Three different concentrations of the standard drug solution were added to the tablet solution of known concentration. The total drug concentration in the final solutions were determined by applying the general analytical procedure. The high precision of the method was revealed from the closeness of the \% recovery to $100 \%$ (Table 3 ). In addition, it was concluded that the presence of tablets excipients did not affect the obtained results and the high selectivity of the suggested procedure.

Two levels of precision were evaluated for the developed method; intra- and inter-day precisions. Three different concentrations $\left(1.0,1.5\right.$ and $\left.2.0 \mu \mathrm{g} \mathrm{mL}{ }^{-1}\right)$ of lisinopril were analysed in three replicates within the same day in case of interday precision or at three successive days for intra-day precision. The relative standard deviation were calculated in each case. It was shown (Table 4 ) that RSD did not exceed $2 \%$ which gives a prove for the high precision of the proposed method.

3.3.4. Robustness. The robustness of the developed method was examined by changing some experimental parameters $(\mathrm{pH}$, buffer volume, fluorescamine concentration and reaction time) during performing the general analytical procedure. The $\%$ recovery and relative standard deviation

Table 2 Comparison of the proposed spectrofluorimetric method with the reported spectrophotometric and spectrofluorimetric methods for the determination of lisinopril

\begin{tabular}{|c|c|c|c|c|c|}
\hline Reagent(s) & Reaction temperature & Reaction time & LOQ $\mu \mathrm{g} \mathrm{mL} \mathrm{L}^{-1}$ & LOD $\mu \mathrm{g} \mathrm{mL}^{-1}$ & Ref. \\
\hline \multicolumn{6}{|l|}{ I. Spectrophotometry } \\
\hline Ninhydrin and sodium molybdate & $90{ }^{\circ} \mathrm{C}$ & $10 \mathrm{~min}$ & 1.30 & 0.39 & 2 \\
\hline Derivative spectrophotometry & $25^{\circ} \mathrm{C}^{b}$ & $0 \mathrm{~min}$ & 1.5 & 0.6 & 4 \\
\hline$o$-Phenylenediamine & $80^{\circ} \mathrm{C}$ & $25 \mathrm{~min}$ & 2.0 & - & 5 \\
\hline Ninhydrin in DMF & $80^{\circ} \mathrm{C}$ & $5 \mathrm{~min}$ & 18.4 & 5.59 & 6 \\
\hline Sodium hypochlorite and phenylhydrazine & $85^{\circ} \mathrm{C}$ & $20 \mathrm{~min}$ & 20 & 5 & 9 \\
\hline Chloranil & $60{ }^{\circ} \mathrm{C}$ & $40 \mathrm{~min}$ & 4.0 & - & 10 \\
\hline \multicolumn{6}{|l|}{ II. Spectrofluorimetry } \\
\hline Acetylacetone and formaldehyde & $\sim 100{ }^{\circ} \mathrm{C}$ & $10 \mathrm{~min}$ & 0.03 & - & 10 \\
\hline${\mathrm{NBD}-\mathrm{Cl}^{a}}^{a}$ & $60^{\circ} \mathrm{C}$ & $70 \mathrm{~min}$ & 0.05 & 0.02 & 11 \\
\hline Fluorescamine & $25{ }^{\circ} \mathrm{C}^{b}$ & $7 \mathrm{~min}$ & 0.55 & 0.18 & This work \\
\hline
\end{tabular}

${ }^{a} \mathrm{NBD}-\mathrm{Cl}$ is 7-chloro-4-nitrobenzofurazan and NQS is 1,2-naphthoquinone-4-sulphonate sodium. ${ }^{b} 25^{\circ} \mathrm{C}$ mean room temperature and $\sim 100{ }^{\circ} \mathrm{C}$ was obtained by heating on a boiling water bath. 
Table 3 Standard addition method for determination of lisinopril in different tablets

\begin{tabular}{|c|c|c|c|c|c|}
\hline \multirow[b]{2}{*}{ No. } & \multirow[b]{2}{*}{ Conc. taken $\left(\mu \mathrm{g} \mathrm{mL}^{-1}\right)$} & \multirow[b]{2}{*}{ Standard added $\left(\mu \mathrm{g} \mathrm{mL}{ }^{-1}\right)$} & \multirow[b]{2}{*}{ Total conc. $\left(\mu \mathrm{g} \mathrm{mL}^{-1}\right)$} & \multicolumn{2}{|l|}{$\%$ recovery } \\
\hline & & & & Maxipril@ $20 \mathrm{mg}$ tablets & Sinopril Co® tablets \\
\hline 1 & 1.0 & 0.5 & 1.5 & 100.73 & 101.44 \\
\hline 2 & 1.0 & 1.0 & 2.0 & 99.35 & 100.64 \\
\hline 3 & 1.0 & 1.5 & 2.5 & 99.36 & 98.90 \\
\hline Mean & & & & 99.82 & 100.33 \\
\hline SD & & & & 0.796 & 1.29 \\
\hline RSD & & & & 0.798 & 1.29 \\
\hline
\end{tabular}

Table 4 Intraday and interday precision of the proposed method

\begin{tabular}{llc}
\hline Precision level & Conc. level $\left(\mu \mathrm{g} \mathrm{mL}^{-1}\right)$ & \% recovery $^{a} \pm \mathrm{RSD}$ \\
\hline Intra-day precision & 1.0 & $101.19 \pm 1.01$ \\
& 1.5 & $97.13 \pm 1.47$ \\
Inter-day precision & 2.0 & $100.55 \pm 1.39$ \\
& 1.0 & $100.63 \pm 1.83$ \\
& 2.0 & $98.75 \pm 0.68$ \\
& & $102.11 \pm 1.18$
\end{tabular}

(RSD) were calculated for each parameters. As shown in Table 5, it is clear that analytical performance of the method did not affected significantly by these variations as good \% recoveries and low RSD were obtained. This gave an indication for the robustness of the proposed method.

3.3.5. Selectivity. To study the selectivity of the method, different tablet excipients that are commonly incorporated in lisinopril dosage forms, in addition to hydrochlorothiazide were added separately to the drug standard solution. The general analytical procedure was applied to find out the drug concentration and the results are expressed in \% recovery $\pm \mathrm{SD}$. As shown in Table 6, it is clear that none of these excipients and hydrochlorothiazide produced any significant interference with the results of the proposed method which give a prove for its selectivity for determination of lisinopril.

Table 5 Robustness of the proposed method for analysis of lisinopril $\left(2 \mu \mathrm{g} \mathrm{mL}^{-1}\right.$ )

\begin{tabular}{lllll}
\hline Optimization factor & Value & \% recovery $^{a}$ & Mean \pm SD & \% RSD \\
\hline Borate buffer pH & 9.3 & 101.19 & $102.34 \pm 1.04$ & 1.01 \\
& 9.5 & 102.60 & & \\
Borate buffer & 9.7 & 103.22 & & \\
volume (mL) & 0.2 & 99.91 & $99.44 \pm 1.23$ & 1.23 \\
& 0.5 & 100.37 & & \\
Reaction time (min) & 5 & 102.68 & $102.54 \pm 0.32$ & 0.32 \\
& 7 & 102.77 & & \\
Fluorescamine & 10 & 102.17 & & \\
volume (mL) & 0.5 & 96.34 & $97.40 \pm 0.93$ & 0.96 \\
& 1 & 98.09 & & \\
& 1.5 & 97.78 & & \\
& & 98.05 & & \\
& & & & \\
\end{tabular}

${ }^{a}$ The value is the average of three determinations.

\subsection{Applications of the proposed method}

3.4.1. Application to pharmaceutical dosage forms. After development and full validation of the proposed analytical procedure, it was successfully applied for analysis of pharmaceutical formulations containing lisinopril either alone or in the presence of hydrochlorothiazide. In the same time the dosage forms were analyzed by a reported method ${ }^{\mathbf{1 0}}$ and the results of both methods were statistically compared regarding the accuracy and precision using Student's $t$-test and $F$-test. It was found that, the calculated values of both parameters did not exceed the theoretical values at 95\% confidence level. This gives an indication about the acceptable level of the reliability of the proposed method Table 7 . The good recoveries obtained gives an evidence for the absence of any significant interference from either tablet excipients or the co-formulated drug, hydrochlorothiazide. It was expected that hydrochlorothiazide could not react with fluorescamine because it do not contain any basic amino group in its structure. As a result it did not interfere with the analysis of lisinopril. Therefore, the method can be a good alternative for the quality control of drug products containing lisinopril.

3.4.2. Content uniformity testing. The content uniformity testing is carried out to guarantee the consistency of pharmaceutical dosage units. Accordingly, each unit in a batch should have a drug substance content within a narrow range around the label claim. ${ }^{38}$ This procedure is a time-consuming process when using conventional assay techniques. However, the proposed method was preferably suitable for testing the content uniformity of lisinopril due to its high sensitivity and fast measurement of the fluorescence intensity of a single tablet extract with sufficient accuracy. The proposed method was successfully adopted to estimate the content uniformity

Table 6 Analysis of lisinopril $\left(2 \mu \mathrm{g} \mathrm{mL}^{-1}\right)$ in presence of the common excipients that are present in its commercially available dosage forms

\begin{tabular}{llc}
\hline Excipients & Amount added $(\mathrm{mg})$ & \% recovery $^{a} \pm \mathrm{SD}$ \\
\hline Maize starch & 10 & $102.10 \pm 1.76$ \\
Mannitol & 10 & $103.59 \pm 0.61$ \\
Magnesium stearate & 10 & $101.01 \pm 0.48$ \\
Dibasic calcium phosphate & 10 & $99.85 \pm 1.74$ \\
Hydrochlorothiazide & 0.012 & $101.46 \pm 1.29$
\end{tabular}

${ }^{a}$ The value is the average of three determinations. 
Table 7 Application of the proposed method on different commercial tablets by both the proposed and the reported ${ }^{10}$ methods

\begin{tabular}{|c|c|c|c|c|}
\hline Dosage forms & \multicolumn{2}{|l|}{$\%$ recovery $^{a} \pm \mathrm{SD}$} & $F$-value & $t$-value ${ }^{b}$ \\
\hline Sinopril Co® tablets & $99.57 \pm 1.42$ & $101.57 \pm 1.49$ & 1.10 & 2.19 \\
\hline
\end{tabular}

Table 8 Results for the content uniformity testing using the proposed method

\begin{tabular}{lll}
\hline & \multicolumn{2}{c}{ \% recovery of the claimed content of tablets } \\
\cline { 2 - 3 } Tablet number & Sinopril@ 10 mg tablets & Sinopril Co® tablets \\
\hline 1 & 100.44 & 97.82 \\
2 & 100.65 & 101.89 \\
3 & 98.42 & 100.33 \\
4 & 103.79 & 101.07 \\
5 & 101.58 & 101.25 \\
6 & 101.71 & 101.89 \\
7 & 100.48 & 101.87 \\
8 & 102.12 & 102.93 \\
9 & 102.99 & 100.38 \\
10 & 97.01 & 96.84 \\
Mean & 100.92 & 100.62 \\
SD & 2.03 & 1.911 \\
RSD & 2.01 & 1.90 \\
Acceptance & 4.87 & 4.59 \\
value (AV) & & \\
Maximum & 15 & \\
allowed AV (L1) & &
\end{tabular}

according to the USP procedures ${ }^{38}$ for tablets extracts of both Sinopril® and Sinopril Co® tablets. The acceptance value (AV) was calculated was found to be less than the maximum allowed acceptance value (L1) which indicates excellent uniformity of the tested dosage forms (Table 8).

\section{Conclusion}

The current work illustrates the development and validation of a simple, rapid, and reliable spectrofluorimetric method for the analysis of dosage forms containing lisinopril. The method overcomes the drawbacks that were found in the previously reported methods and was applied successfully for content uniformity testing of dosage forms containing the cited drug. In addition, the proposed method is highly selective since it could determine lisinopril in the presence of the co-formulated drug, hydrochlorothiazide, without any possible interference. Consequently, the suggested method can be applied in quality control analysis of lisinopril owing to its improved simplicity, sensitivity and their independence on expensive instruments.

\section{Conflicts of interest}

There are no conflicts to declare.

\section{References}

1 L. L. Brunton, J. S. Lazo and K. S. Parker, Goodman \& Gilman's the Pharmacological Basis of Therapeutics, $11^{\text {th }}$ edn, 2006.

2 P. Nagaraja, A. K. Hrestha, A. Shivakumar and N. G. S. AlTayar, J. Food Drug Anal., 2011, 19, 85-93.

3 A. A. A. Ali and A. A. Elbashir, Am. Acad. Sch. Res. J., 2013, 5, 106.

4 A. El-Gindy, A. Ashour, L. Abdel-Fattah and M. M. Shabana, J. Pharm. Biomed. Anal., 2001, 25, 923-931.

5 C. Jamakhandi, C. Javali, J. Disouza, U. Chougule and A. Mullani, Int. J. Pharm. Pharm. Sci., 2011, 3, 185-187.

6 A. Raza, T. M. Ansari and R. Atta-ur, J. Chin. Chem. Soc., 2005, 52, 1055-1059.

7 O. A. Razak, S. Belal, M. Bedair, N. Barakat and R. Haggag, J. Pharm. Biomed. Anal., 2003, 31, 701-711.

8 G. Paraskevas, J. Atta-Politou and M. Koupparis, J. Pharm. Biomed. Anal., 2002, 29, 865-872.

9 A. El-Gindy, A. Ashour, L. Abdel-Fattah and M. M. Shabana, J. Pharm. Biomed. Anal., 2001, 25, 913-922.

10 F. A. El-Yazbi, H. H. Abdine and R. A. Shaalan, J. Pharm. Biomed. Anal., 1999, 19, 819-827.

11 E. S. Aktas, L. Ersoy and O. Sagirlı, Il Farmaco, 2003, 58, 165168.

12 C. Jamakhandi, C. Javali, S. Kumar, S. Kumar and D. S. Sanjay-Kumar, Int. J. Pharm. Sci. Drug Res., 2010, 2, 182-187.

13 C. Jamkhandi, C. Javali, S. Kumar and D. Kadadevar, Int. J. Pharmacol. Pharm. Sci., 2010, 2, 209-211.

14 S. M. Derayea, K. M. Badr El-Din and F. F. Mohammed, Luminescence, 2017, 32, 1482-1487.

15 S. M. Derayea, K. M. B. El-din and F. F. Mohammed, Spectrochim. Acta, Part A, 2018, 188, 318-323.

16 F. Elsebaei and Y. Zhu, Talanta, 2011, 85, 123-129.

17 C. A. Beasley, J. Shaw, Z. Zhao and R. A. Reed, J. Pharm. Biomed. Anal., 2005, 37, 559-567.

18 D. Bonazzi, R. Gotti, V. Andrisano and V. Cavrini, J. Pharm. Biomed. Anal., 1997, 16, 431-438.

19 S. Bouabdallah, H. Trabelsi, K. Bouzouita and S. Sabbah, J. Biochem. Biophys. Methods, 2002, 54, 391-405.

20 E. R. Dawud and A. K. Shakya, Arabian J. Chem., 2014, DOI: 10.1016/j.arabjc.2014.10.052. 
21 A. A. El-Emam, S. H. Hansen, M. A. Moustafa, S. M. El-Ashry and D. T. El-Sherbiny, J. Pharm. Biomed. Anal., 2004, 34, 3544.

22 C. Kousoulos, G. Tsatsou, Y. Dotsikas and Y. L. Loukas, Anal. Chim. Acta, 2005, 551, 177-183.

23 V. Kumar, R. P. Shah and S. Singh, J. Pharm. Biomed. Anal., 2008, 47, 508-515.

24 Y. X. Liu, D. Shou, M. L. Chen, Z. D. Chen, P. M. Zhang and Y. Zhu, Chin. Chem. Lett., 2012, 23, 335-338.

25 V. Maslarska and J. Tencheva, Int. J. Pharm. Biol. Sci., 2013, 4, 163-167.

26 P. G. Nagaraju, A. Bilal and V. Siddhartha, Int. J. Chem. Pharm. Sci., 2014, 2, 635-641.

27 J. V. Odovic, B. D. Markovic, R. D. Injac, S. M. Vladimirov and K. D. Karljikovic-Rajic, J. Chromatogr. A, 2012, 1258, 94-100. 28 O. Sagirli and L. Ersoy, J. Chromatogr. B, 2004, 809, 159-165. 29 V. M. Sarma, Int. J. Curr. Res. Acad. Rev., 2015, 3, 226-233.

30 Y.-c. Wong and B. G. Charles, J. Chromatogr. B: Biomed. Sci. Appl., 1995, 673, 306-310.

31 A. A. Padua, R. E. Barrientos-Astigarraga, V. M. Rezende, G. D. Mendes and G. De Nucci, J. Chromatogr. B, 2004, 809, 211-216.

32 S. Hillaert and W. Van den Bossche, J. Chromatogr. A, 2000, 895, 33-42.

33 S. Hillaert and W. Van den Bossche, J. Pharm. Biomed. Anal., 2001, 25, 775-783.
34 S. Hillaert, Y. Vander Heyden and W. Van den Bossche, J. Chromatogr. A, 2002, 978, 231-242.

35 R. Gotti, V. Andrisano, V. Cavrini, C. Bertucci and S. Furlanetto, J. Pharm. Biomed. Anal., 2000, 22, 423-431.

36 C. K. Zacharis, P. D. Tzanavaras, D. G. Themelis, G. A. Theodoridis, A. Economou and P. G. Rigas, Anal. Bioanal. Chem., 2004, 379, 759-763.

37 A. Yuan and J. Gilbert, J. Pharm. Biomed. Anal., 1996, 14, 773781.

38 M. Rockville, The United States Pharmacopoeia 30, The National Formulary 25 US Pharmacopeial Convention, Electronic version, 2007.

39 M. Weigele, S. L. DeBernardo, J. P. Tengi and W. Leimgruber, J. Am. Chem. Soc., 1972, 94, 5927-5928.

40 A. A. Savina, O. N. Tolkachev, V. I. Sheichenko and V. V. Proskudina, Pharm. Chem. J., 1999, 33, 25-28.

41 S. De Bernardo, M. Weigele, V. Toome, K. Manhart, W. Leimgruber, P. Böhlen, S. Stein and S. Udenfriend, Arch. Biochem. Biophys., 1974, 163, 390-399.

42 ICH Harmonized Tripartite Guideline, Validation of analytical procedures: text and methodology Q2 (R1), Geneva, 2005, available at: http://www.ich.org/fileadmin/Public_Web_Site/ ICH_Products/Guidelines/Quality/Q2_R1/Step4/ Q2_R1_Guideline.pdf, [accessed 27 April, 2018]. 